\title{
Diverse Enhancement of Superoxide Production from Kupffer Cells and Neutrophils after Burn Injury or Septicemia
}

\author{
Yuhko Masuda ${ }^{1}$, Manabu Kinoshita ${ }^{2, *}$, Satoshi Ono ${ }^{1}$, Hironori Tsujimoto ${ }^{1}$, \\ and Hidetaka Mochizuki ${ }^{1}$ \\ ${ }^{1}$ Department of Surgery 1, National Defense Medical College, Namiki 3-2, Tokorozawa 359-8513, Japan \\ ${ }^{2}$ Division of Basic Traumatology, National Defense Medical College Research Institute, Namiki 3-2, \\ Tokorozawa 359-8513, Japan
}

Received 31 May, 2005; Accepted 20 October, 2005

Summary Objective: To investigate the difference in superoxide production from circulating neutrophils and Kupffer cells between in the mice after burn injury and mice suffering from bacterial septicemia.

Background: Both severe burn injury and septicemia can result in a critical/fatal outcome for the patients even after initial resuscitation. Analyses of defense mechanisms in the host who survive after severe stress are thereby very important for improvement of intensive care.

Method: Either burn injury or inoculations with Peudomonas aeruginosa were subjected to C57BL/6 mice. After 7 days, circulating neutrophils and Kupffer cells were obtained from the mice to examine superoxide or cytokine production.

Results: Neither of the mouse groups showed any pathological changes in major organs or any elevations in the serum transaminase or TNF levels at 7 days after burn injury or bacterial inoculation. The burn injured mice showed significantly higher superoxide production from neutrophils by stimulation with phorbor myristate acetate (PMA) or opsonized zymosan $(\mathrm{OZ})$ than that from Kupffer cells. In contrast, the bacterial challenged mice showed a significantly higher superoxide production from Kupffer cells than that from neutrophils. In addition, the burn injured mice showed a significantly higher production of IL-10, namely antiinflammatory cytokine, from the Kupffer cells by LPS stimulation than the bacterial challenged mice while the bacterial challenged mice showed a significantly higher production of IL-12, namely proinflammatory cytokine, from Kupffer cells by LPS stimulation than the burn injured mice.

Conclusions: Neutrophils might thus be activated to a greater degree than Kupffer cells in mice after burn injury, while Kupffer cells might be activated more than neutrophils after bacterial septicemia.

Key Words: burn injury, Pseudomonas aeruginosa, superoxide anion, Kupffer cells, neutrophils

\section{Introduction}

Both Kupffer cells and neutrophils play important roles in

\footnotetext{
*To whom correspondence should be addressed

Tel: +81-4-2995-1633 Fax: +81-4-2991-1613

E-mail: manabu@ndmc.ac.jp
}

the first line of host defense, because they produce superoxide anions in response to certain stimuli. Superoxide anions play an essential role in the phagocytosis of these cells [1-5]. However, excessively activated superoxide anions are also known to impair the host due to oxidative stress. Clinically, burn injury and bacterial septicemia are considered as severe critical stress. The former is an aseptic stress while the later is a septic stress. Such severe stresses 
induce exaggerated inflammatory reactions in which the activated Kupffer cells and/or neutrophils are involved [6-10]. In the agonal phase, these severe stresses are often associated with multiple organ dysfunctions due to extremely exaggerated inflammation $[11,12]$. Even if the patients survive the initial insult, various complications often occur in such critical patients during the subsequent recovery phase. We previously demonstrated that the impaired immune function following burn injury is most strongly evident at 7 days after injury in the mice [13]. On the other hand, we also reported that the immune function of the mice subjected to cecal ligation and puncture (CLP) still impairs at 7 days after injury [14]. These findings suggest that the host immune system impair not only at the initial agonal phase but also at the subsequent recovery phase of the inflammatory reaction such as burn injury and bacterial septicemia. We thereby think that these critical stresses seriously alter the functions of Kupffer cells and neutrophils even in their recovery phases. Nevertheless, there have been few comparative studies focusing on the difference in the immune function at the recovery phases between aseptic burn injury and bacterial septicemia. Investigations of the recovery phase are a very important and significant aspect of inflammatory reaction for host defense. In the present study, we therefore investigated the difference in Kupffer cell and neutrophil activation between in the mice after burn injury and those after Pseudomonas aeruginosa ( $P$. aeruginosa) septicemia, while focusing on the superoxide and cytokine production.

\section{Materials and Methods}

\section{Animals and reagents}

Male C57BL/6 mice were studied (8 weeks old, $20 \mathrm{~g}$, Charles River Inc, Yokohama, Japan). P. aeruginosa (strain PSK, ATCC 227835) was grown in a brain heart infusion broth and stored at $-80^{\circ} \mathrm{C}$ until use. The intravenous injection dose of $P$. aeruginosa which produced a $50 \%$ lethality (LD50) was $5 \times 10^{8}$ colony-forming units (CFU).

This study was conducted according to the guidelines of the Institutional Review Board for the Care of Animal Subjects at the National Defense Medical College Japan.

2-methyl-6-[P-methoxyphenyl]-3,7-dihydroimidazo[1.2a]pyrazin-3-one (MCLA, Tokyo Kasei Kogyo Co., Tokyo) is a sensitive chemiluminescence probe for the identification of both $\mathrm{O}_{2}{ }^{-}$and ${ }^{1} \mathrm{O}_{2}$ generated in biological systems. MCLA was dissolved in a concentration of $200 \mu \mathrm{M}$ in distilled water and then was stored in $1 \mathrm{ml}$ aliquots, at $-80^{\circ} \mathrm{C}$ until use. Phorbor myristate acetate (PMA, Sigma Chemical Co., St. Louis, MO) was suspended in a concentration of $10 \mathrm{mg}$ / $\mathrm{ml}$ in DMSO, and stored at $-80^{\circ} \mathrm{C}$ until use. To prepare the opsonized zymosan (OZ), $4 \mathrm{mg} / \mathrm{ml}$ of zymosan (Sigma Chemical Co.) suspended in $20 \mathrm{mM}$ beronal buffer at PH 7.4 was boiled for $100 \mathrm{~min}$, and then was cooled to room temperature. After centrifugation for $10 \mathrm{~min}$ at $1900 \mathrm{~g}$, and the zymosan was added to pooled mouse serum at $1900 \mathrm{~g}$, zymosan was washed twice with Hank's balanced solution (HBSS). The resulting OZ was then suspended in a concentration of $20 \mathrm{mg} / \mathrm{ml}$ in $\mathrm{HBSS}$, and stored at $-80^{\circ} \mathrm{C}$ until use.

\section{Burn injury and bacterial challenge}

To induce severe aseptic injury, burn injury was performed as previously described [13, 16]. Briefly, under deep ether anesthesia, after shaving, the mice were placed in a plastic mold that exposes $20 \%$ of their total body surface area. The mice were then subjected to full-thickness burn injury by pressing a heated brass blade to the skin. To induce severe septic injury, a bacterial challenge was performed by the i.v. injection of $1 \times 10^{8} \mathrm{CFU}$ of $P$. aeruginosa into the mice.

\section{Isolation of Kupffer cells}

The isolation of Kupffer cells was performed as previously described [16, 17]. Briefly, under deep ether anesthesia, the mice were sacrificed by bleeding, and then the livers were removed. The livers were minced and suspended in a RPMI 1640 medium containing $0.05 \%$ collagenase (Wako, Osaka, Japan). Which was then shook for $20 \mathrm{~min}$ in a $37^{\circ} \mathrm{C}$ water bath. Thereafter, the liver specimen was passed through a stainless steel mesh and then was suspended in the medium. After one washing, the cells were resuspended in osmolarity and $\mathrm{pH}$-adjusted $33 \%$ Percoll solution containing $100 \mathrm{U} / \mathrm{ml}$ heparin and they were centrifuged at $500 \mathrm{~g}$ for $20 \mathrm{~min}$ at room temperature. The pellet was resuspended in a red blood cell lysis solution, and then was washed twice in 10\% FBS RPMI 1640. The extracted mononuclear cells suspended at $2.5 \times 10^{6} / \mathrm{ml}$ in 10\% FBS RPMI1640 medium were cultured in collagen-coated plastic plates for $2 \mathrm{~h}$ at $37^{\circ} \mathrm{C}$ in $5 \% \mathrm{CO}^{2}$. After removing the non-adherent lymphocytes by gentle pipetting, adherent Kupffer cells were obtained with a cell scraper.

\section{Isolation of neutrophils}

The isolation of neutrophils was performed by the method described by Rosen and Klebanoff [16, 18]. Briefly, a blood sample was drawn into a heparinized syringe (20 units $/ \mathrm{ml}$ of heparin) from the abdominal aorta following a laparotomy under lethal ether anesthesia. Leukocytes were then isolated by dextrane sedimentation and hypotonic lysis of erythrocytes. The resultant leukocytes which contained 65-90\% neutrophils were suspended in $1 \times 10^{6}$ cells $/ \mathrm{ml} \mathrm{HBSS}$. The purity of the neutrophils was assessed by microscopy using Wright-Giemsa stained cytospins. 
Determination of the superoxide production from Kupffer cells and neutrophils

The superoxide production from Kupffer cells was determined by MCLA-dependent chemiluminescence using the method of Nakano $[16,19,20]$. A glass cuvette containing isolated Kupffer cells $\left(1 \times 10^{5}\right)$ and MCLA $(2 \mu \mathrm{M})$ in $2.0 \mathrm{ml}$ of HBSS was placed in a luminescence reader (BLR-101, Aloka, Tokyo) and the emission of chemiluminescence was recorded. After keeping the cuvette at $37^{\circ} \mathrm{C}, 4 \mu \mathrm{g}$ of PMA or $2 \mathrm{mg}$ of $\mathrm{OZ}$ was added to the cuvette to determine the superoxide production stimulated by either PMA or OZ respectively. After the addition of stimulants, superoxide dismutase (SOD) (final concentration: $0.5 \mu \mathrm{M}$, Sigma Chemical Co.) was added to assess the role of superoxide anion in the MCLA-dependent chemiliminescence emission from Kupffer cells. Similarly, superoxide production from neutrophils was also determined by MCLA-dependent chemiluminescence. A glass cuvette containing neutrophils $\left(1 \times 10^{5}\right)$ and MCLA was placed in the luminescence reader. Thereafter, PMA or OZ was added to the respective cuvette to stimulate superoxide production.

Determination of cytokine productions from Kupffer cells by LPS stimulation

To determine the cytokine production from Kupffer cells, Kupffer cells $\left(5 \times 10^{5}\right)$ in $200 \mu$ of $10 \%$ FBS RPMI 1640 medium were cultured with $2 \mu \mathrm{g}$ of LPS in 96-well flatbottom plates for $24 \mathrm{~h}$ at $37^{\circ} \mathrm{C}$ in $5 \% \mathrm{CO}_{2}$. Culture supernatants were stored at $-80^{\circ} \mathrm{C}$ until assay. Interleukin (IL)-10, IL-12 and IL-18 levels in the culture supernatants were measured using respective cytokine-specific ELISA kits (IL-10 and IL-12: Endogen, Worburn, MA, IL-18: MBL, Nagoya, Japan).

\section{Determination of the serum transaminase and TNF levels}

Blood samples were drawn from the abdominal aorta following a laparotomy under lethal ether anesthesia. Using the obtained serum samples, the serum aspartate aminotransferase (AST) and alanine aminotransferase (ALT) levels were measured using the FUJI dry-chem system (FUJI FILLM, Tokyo, Japan), while the serum TNF levels were also measured using a TNF specific ELISA kit (Endogen).

\section{Viable bacterial counts in the liver}

The livers were aseptically removed in the same way as described above to produce a homogenized PBS in the suspension. The serially 10 -fold diluted homogenates by PBS in the organs were placed on to brain heart infusion agar plates and then were incubated at $37^{\circ} \mathrm{C}$ for $24 \mathrm{~h}$. The number of viable bacteria in the liver was then counted according to the observed colonies on the agar plates.

\section{Pathological examinations}

Under deep ether anesthesia, the mice were sacrificed by bleeding. Subsequently the lungs, the livers, kidneys and small intestines near the terminal ileum were removed. The lungs were then immersed in $20 \%$ formalin for 2 days, after the intra-tracheal instillation of $20 \%$ formalin. The livers, kidneys and small intestines were also immersed in $20 \%$ formalin for 2 days. From these specimens, slides were prepared and stained with hematoxylin and eosin.

\section{Statistical analysis}

The data are presented as the mean values \pm SE. Differences between the groups were analyzed by the MannWhitney U test, ANOVA with Fisher's protected least significant difference test, or Scheffe's F test using the Stat View software program (Abacus Concepts, Berkeley, CA) on an Apple computer (Cuperthino, CA). Differences were considered to be significant at $\mathrm{P}<0.05$.

\section{Results}

No significant difference in the background conditions was observed between the mice after burn injury and bacterial challenge

None of the mice died due to the induced burn injury or bacterial challenge. At 7 days after injuries, no TNF was detectable in the sera either of the burn injured or bacterial challenged mice. In addition, no significant elevations in either the serum AST nor ALT levels were found in either of the mouse group (Table 1), while, no significant pathological findings were observed in either group (Fig. 1, 2). Furthermore, no viable bacterium in the liver or lung was observed in either of the group.

Table 1. Serum AST and ALT levels in the mice at 7 days after burn injury or bacterial challenges

\begin{tabular}{lcccc}
\hline & $\begin{array}{c}\text { burn injured mice } \\
(\mathrm{n}=7)\end{array}$ & $\begin{array}{c}\text { bacterial challenged mice } \\
(\mathrm{n}=7)\end{array}$ & $\begin{array}{c}\text { non-treated control mice } \\
(\mathrm{n}=7)\end{array}$ & \\
\hline AST $(\mathrm{U} / 1)$ & $42.5 \pm 6.4$ & $38.5 \pm 12.0$ & $35.0 \pm 6.6$ & n.s. \\
ALT $(\mathrm{U} / \mathrm{l})$ & $22.5 \pm 7.8$ & $17.0 \pm 5.6$ & $13.7 \pm 3.9$ & n.s.
\end{tabular}

The sera were obtained from the mice at 7 days after burn injury or $P$. aeruginosa challenges to measure the serum AST and ALT levels. The sera were also obtained from the non-treated normal mice as a control. Data are the means \pm SE.

Vol. 38, No. 1, 2006 

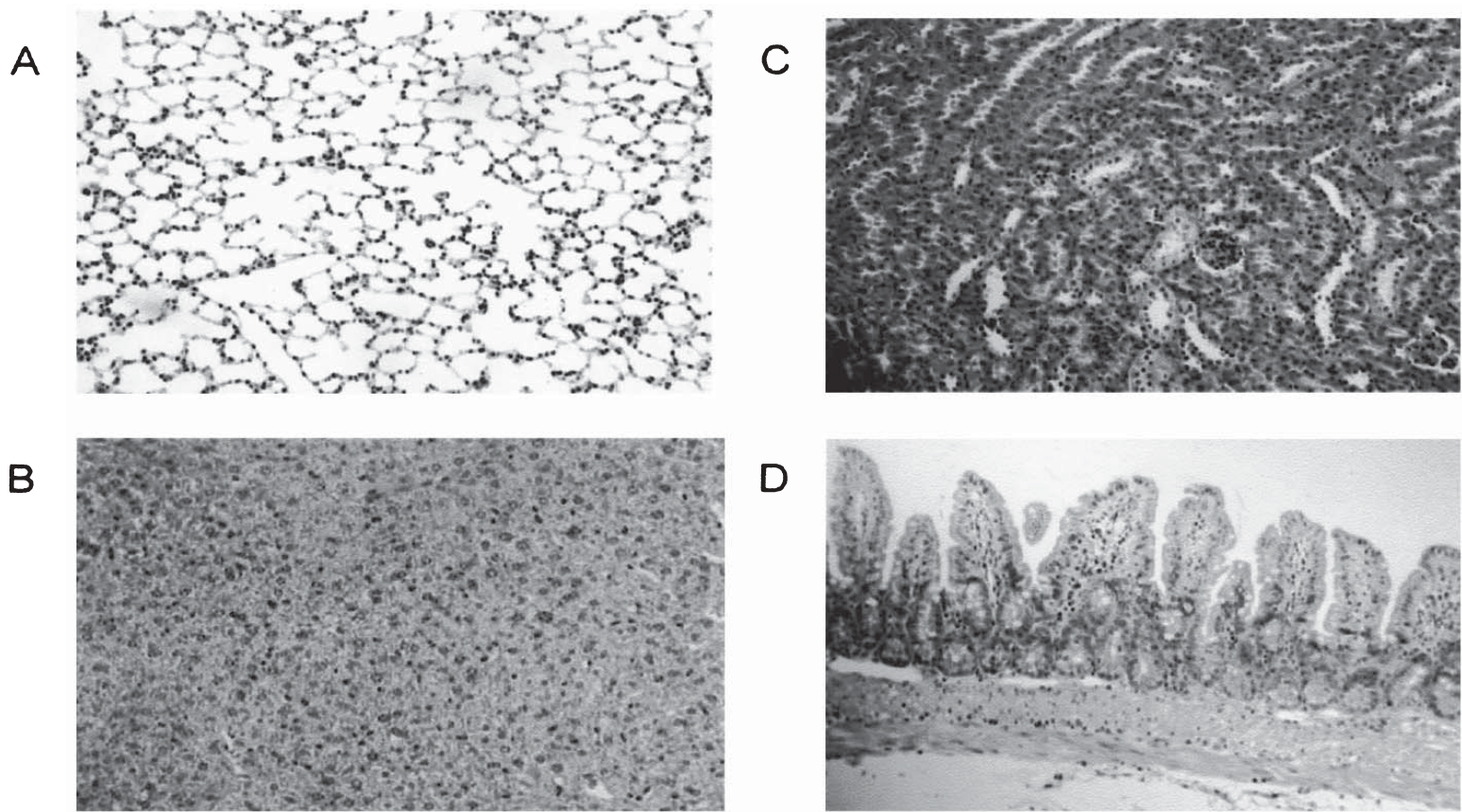

Fig. 1. The pathological findings of the livers (A), the lungs (B), the kidneys (C) and the small intestines (D) in the mice at 7 days after burn injury. The livers, lungs, kidneys and small intestines near the terminal ileum were removed from the mice $(n=5)$ at 7 days after burn injury. Hematoxylin and eosin stain; original magnification 100. Representative findings are shown.
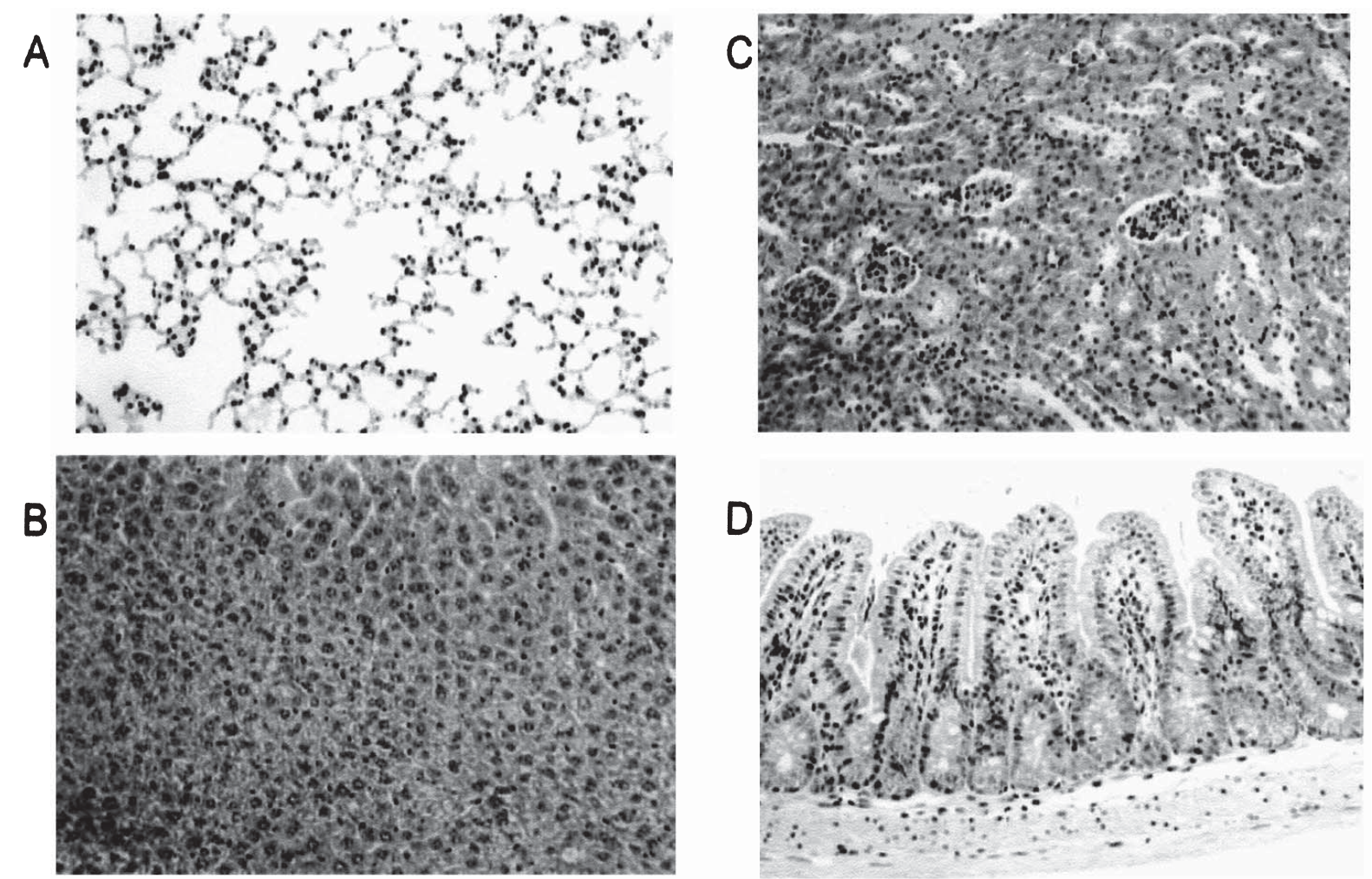

Fig. 2. The pathological findings of the livers (A), the lungs (B), the kidneys (C) and the small intestines (D) in the mice at 7 days after $P$. aeruginosa challenge. The livers, lungs, kidneys and small intestines near the terminal ileum were removed from the mice $(\mathrm{n}=5)$ at 7 days after $P$. aeruginosa challenge. Hematoxylin and eosin stain; original magnification $\times 100$. Representative findings are shown. 
Table 2. Superoxide production of Kupffer cells and neutrophils in the un-treated normal mice

\begin{tabular}{lccc}
\hline & $\begin{array}{c}\text { Kupffer cells } \\
\text { from normal mice } \\
(\mathrm{n}=7)\end{array}$ & $\begin{array}{c}\text { Neutrophils } \\
\text { from normal mice } \\
(\mathrm{n}=7)\end{array}$ & \\
\hline PMA stimulation $\left(\times 10^{3} \mathrm{cpm}\right)$ & $9.6 \pm 1.6$ & $9.9 \pm 2.2$ & n.s. \\
OZ stimulation $\left(\times 10^{3} \mathrm{cpm}\right)$ & $18.0 \pm 2.8$ & $23.1 \pm 3.2$ & n.s. \\
Non-stimulation $\left(\times 10^{3} \mathrm{cpm}\right)$ & $4.7 \pm 0.4^{*}$ & $4.5 \pm 0.8^{*}$ & n.s. \\
\hline
\end{tabular}

$1 \times 10^{8}$ of Kupffer cells or neutrophils were obtained from the normal mice and then stimulated with PMA or $\mathrm{OZ}$ to measure superoxide production, which is assessed by MCLA dependent chemiluminescence. Data are the means $\pm \mathrm{SE} . * \mathrm{P}<0.01$ vs. PMA and $\mathrm{OZ}$ stimulation.

Neutrophils enhanced superoxide production more than Kupffer cells in the mice at 7 days after burn injury

Kupffer cells and circulating neutrophils were obtained from the non-treated normal mice. No difference in superoxide production induced by either PMA or OZ stimulation was observed between the Kupffer cells and neutrophils of the normal mice, although both Kupffer cells and neutrophils produced a certain amount of superoxide anion by the PMA or OZ stimulation (Table 2). Next, Kupffer cells and circulating neutrophils were obtained from the mice at 7 days after burn injury. Interestingly, the neutrophils showed a significantly higher superoxide production induced by either PMA or OZ stimulation than Kupffer cells in the burn injured mice (Fig. 3).
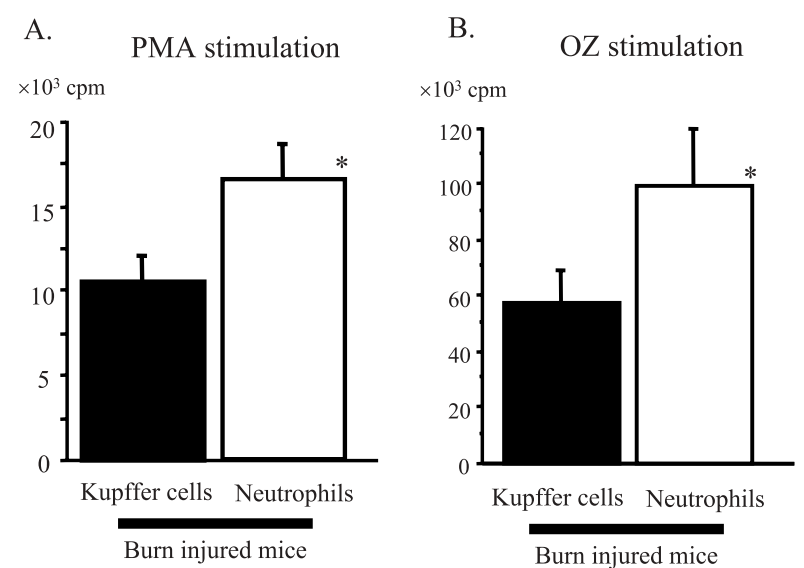

Fig. 3. The superoxide production, as assessed by MCLAdependent chemiluminescence, of the Kupffer cells and neutrophils based on either PMA (A) or OZ (B) stimulation at 7 days after burn injury. Kupffer cells and neutrophils were isolated from the mice at 7 days after burn injury. MCLA-dependent chemiluminescence was induced by either PMA or OZ stimulation. The data are the means \pm SE from 7 mice in each group. ${ }^{*} \mathrm{P}<0.01$ vs another group.
Kupffer cells enhanced superoxide production more than neutrophils in the mice at 7 days after bacterial challenge

Kupffer cells and circulating neutrophils were also obtained from the mice at 7 days after $P$. aeruginosa challenge. In contrast to the burn injured mice, Kupffer cells showed a significantly higher superoxide production induced by either PMA or OZ stimulation than the neutrophils in the bacterial challenged mice (Fig. 4).

Burn injured mice showed a significantly higher IL-10 production but a significantly lower IL-12 production from Kupffer cells by LPS stimulation compared to bacterial challenged mice.

At 7 days after burn injury or bacterial challenge, Kupffer cells were isolated from the mice. As a control, Kupffer cells
A.

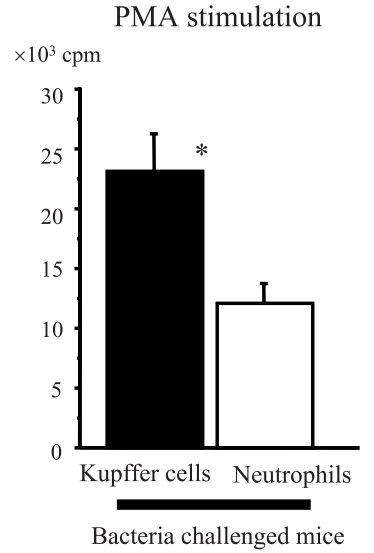

B.

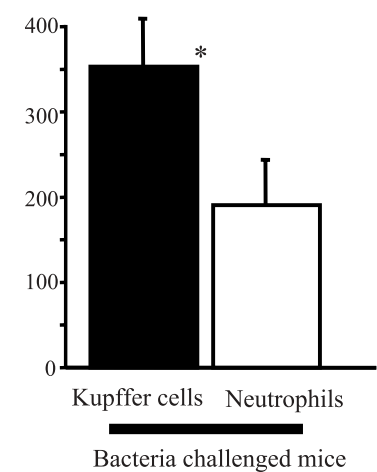
$\times 10^{3} \mathrm{cpm}$ OZ stimulation

Fig. 4. The superoxide production, as assessed by MCLAdependent chemiluminescence, of Kupffer cells and neutrophils based on either PMA (A) or OZ (B) stimulation at 7 days after the $P$. aeruginosa challenge. Kupffer cells and neutrophils were isolated from the mice at 7 days after $P$. aeruginosa challenge. MCLAdependent chemiluminescence was induced by either PMA or OZ stimulation. The data are the means $\pm \mathrm{SE}$ from 7 mice in each group. ${ }^{*} \mathrm{P}<0.01$ vs another group. 
Table 3. Cytokines production of Kupffer cells after burn injury or bacterial challenge

\begin{tabular}{lccc}
\hline & $\begin{array}{c}\text { burn injured mice } \\
(\mathrm{n}=5)\end{array}$ & $\begin{array}{c}\text { bacterial challenged mice } \\
(\mathrm{n}=5)\end{array}$ & $\begin{array}{c}\text { non-treated control mice } \\
(\mathrm{n}=5)\end{array}$ \\
\hline $\mathrm{IL}-10(\mathrm{pg} / \mathrm{ml})$ & $1243 \pm 317^{*}$ & $608 \pm 139^{*}$ & not detected \\
$\mathrm{IL}-12(\mathrm{pg} / \mathrm{ml})$ & $316 \pm 77$ & $962 \pm 87^{* *}$ & $430 \pm 108$ \\
\hline
\end{tabular}

Kupffer cells $\left(5 \times 10^{8}\right)$ were cultured with LPS for $24 \mathrm{~h}$ Then the culture supernatants were measured for cytokines concentration using ELISA kits. Data are the means $\pm \mathrm{SE}$. ${ }^{*} \mathrm{P}<0.05,{ }^{*} \mathrm{P}<0.01$ vs. other groups.

were also isolated from the non-treated control mice. Subsequently, the obtained Kupffer cells were cultured for $24 \mathrm{~h}$ with LPS stimulation to measure IL-10, IL-12 and IL18 productions. Although the IL-10 production of Kupffer cells was below the detection level in the normal mice, both Kupffer cells from the burn injured and bacterial challenged mice produced a significant amount of IL-10 by the LPS stimulation. However, Kupffer cells from the burn injured mice showed a significantly higher IL-10 production than those from the bacterial challenged mice (Table 3). In contrast, Kupffer cells from the bacterial challenged mice showed a significantly higher IL-12 production than those from the burn injured mice and normal mice (Table 3 ). The IL-18 production was below detection levels among the three mouse groups.

\section{Discussion}

Neutrophils enhanced the superoxide production with either PMA or OZ stimulation more than Kupffer cells in the mice at 7 days after burn injury while Kupffer cells enhanced the superoxide production more than neutrophils in the mice at 7 days after bacterial challenge. In addition, the burn injured mice showed a significantly higher IL-10 production but a significantly lower IL-12 production from Kupffer cells by LPS stimulation than those of the bacterial challenged mice. These results suggest that burn injury activates neutrophils more than Kupffer cells while bacterial septicemia activates Kupffer cells more than neutrophils in such mice during their recovery phases.

After burn injury, large amounts of chemokines, which strongly activate neutrophils, are produced and released from the burned lesion. On the other hand, $70 \%$ of the bacteria that enter the blood stream accumulate in the liver, and they are then trapped and removed from the blood by Kupffer cells and hepatocytes $[21,22]$. We think that these findings are one of the reasons why neutrophils are activated after burn injury, and Kupffer cells are activated after bacterial challenge. Therefore, it is possible that burn injured mice tend to be associated with lung injury, such as acute respiratory distress syndrome (ARDS), due to an excessively activated superoxide production of neutrophils, while mice with severe septicemia also tend to be associated with liver injury, such as hepatic failure with sever jaundice, due to an excessively activated superoxide production of Kupffer cells. On the other hand, we think that either burn injury or bacterial challenge might affect the lung function as well as the liver, although no significant pathological findings or bacterial colonization were observed. Interestingly, Robert et al. reported that burn injury delayed the pulmonary and systemic bacterial clearance in the mice using a $P$. aeruginosa infection model [23]. We are interested in the function of the lung, in particular alveolar macrophages, after burn injury and bacterial septicemia. Further study on the lung function following these critical stresses should be done.

Granulocyte colony-stimulating factor (G-CSF) increases neutrophil production and augments its function, including chemotaxis and superoxide production. G-CSF therapy thereby seems to be efficacious against bacterial infection, because neutrophils play an important role in the acute response of the host to bacterial infections [24]. However, we should be careful to augment neutrophil function in the burn-injured hosts, because it might possibly induce an over production of superoxide anions from the neutrophils. An excessive amount of superoxide anions might cause an acute lung injury. On the other hand, Kupffer cells of the mice at 7 days after burn injury produced a significantly higher amount of IL-10 that is an anti-inflammatory cytokine but produced a significantly lower amount of IL-12 that is a proinflammatory cytokine by LPS stimulation than the Kupffer cells of the mice at 7 days after bacterial innoculation. Because cytokine-induced inflammatory response is crucial for the host defense against bacterial infection, treatment of up-regulating IL-12 production but down-regulating IL-10 production in the Kupffer cells might effectively restore the anti-bacterial immune function, which is an inflammatory response, in the burn injured hosts. It is well known that IL-12 induces IFN- $\gamma$ production, which is the most powerful pro-inflammatory cytokine $[25,26]$. In the present study, LPS-induced IFN- $\gamma$ production from the liver lymphocytes of the burned mice significantly suppressed more than those of the normal mice and the bacterial challenged mice (data not shown). IL-18 also induces IFN- $\gamma$ production in the presence of IL-12 [27, 28]. Our recent study showed that IL-18 treatment to the mice up-regulates the IFN- $\gamma$ produc- 
tion after burn injury and improves the mouse mortality of subsequent infections [13, 29]. A therapy using IFN- $\gamma$ inducing factor, namely IL-12 or IL-18, can thus be a potent therapeutic tool against severe bacterial infection in immunocompromised hosts such as burn injured patients [13, 29-33].

Severe septic patients are often complicated with neutropenia. Furthermore, their neutrophil functions are also injured. These patients thereby seriously impair the host defense mechanism against bacterial infections, because their neutrophils are insufficient in quantity and quality to eliminate bacteria. G-CSF therapy might benefit these patients. In the present study, Kupffer cells produced large amount of IL-12 by LPS stimulation in the bacterial challenged mice. Hepatic lymphocytes also produced large amount of IFN- $\gamma$ in these mice (data not shown), suggesting augmentation of inflammatory response. Excessively activated Kupffer cells induce exaggerated inflammatory reactions in the liver and thereby cause liver injury. The down-regulation of these Kupffer cell activity may also be an effective mechanism for the recovery of severe septic patients particularly complicated with bacteria-induced liver dysfunction.

\section{References}

[1] Akunda, J.K., Ahrens, F.A., and Kremer, T.T.: Evaluation of phagocytosis, bactericidal activity, and production of superoxide anion nitric oxide, and tumor necrosis factoralpha in Kupffer cells of neonatal pigs. Am. J. Vet. Res., 62, 1040-1045, 2001.

[2] Bautista, A.P. and Spitzer, J.J.: Role of Kupffer cells in the ethanol - induced oxidative stress in the liver. Front. Biosci., 15, D589-595, 1999.

[3] Yokoyama, H., Fukuda, M., Okamura, Y., Mizukami, T., Ohgo, H., Kamegaya, Y., Kato, S., and Ishii, H.: Superoxide anion release into the hepatic sinusoid after an acute ethanol challenge and its attenuation by Kupffer cell depletion. Alcohol, Clin. Exp. Res., 23, 71S-75S, 1999.

[4] Klebanoff, S.J.: Oxygen metabolism and the toxic properties of phagocytes. Ann. Interm. Med., 93, 480-489, 1980.

[5] Babior, B.M.: Oxidants from Phagocytes: Agents of defense and destruction. Blood., 64, 959-966, 1984.

[6] Kelly, J.L., O’Sullivan, C., O'Riordain, M., O'Riordain, D., Lyoms, A., Doherty, T., Mannick, J.A., and Rodrick, M.R.: Is circulating endotoxin the trigger for the systemic inflammatory response syndrome seen after injury? Amm. Surg., 225, 530-541, 1997.

[7] O’Sullivan, S.T. and O'Connor, T.P.F.: Immunosuppression following thermal injury.: The pathogenesis of immunodysfunction. Br. J. Plast. Surg., 50, 615-623, 1997.

[8] Sparkes, B.G.: Immunological responses to thermal injury. Burns., 23, 106-113, 1997.

[9] Dhainaut, J.F., Marin, N., Mignon, A., and Vinsonneau, C.: Hepatic response to sepsis. Crit. Care. Med., 29, S42-47,
2001.

[10] Ito, Y., Lukita, Atmadja, W., Machen, N.W., Baker, G.L., and Mc Cuskey, R.S.: High dose of intravenous immunoglobulin $\mathrm{G}$ enhance Kupffer cell phagocytic function during the late phase of sepsis and endotoxemia in rats. Shock, 13, 485-491, 2000.

[11] Tjardes, T. and Neugebauer, E.: Sepsis research in the next millennium: concentrate on the software rather than the hardware. Shock, 17, 1-8, 2002.

[12] Sheng, Z.: Prevention of multiple organ dysfunction syndrome in patients with extensive deep burns. Chin. J. Traumal., 5, 195-199, 2002.

[13] Ami, K., Kinoshita, M., Yamauchi, A., Nishikage, T., Habu, Y., Shinomiya, N., Iwai, T., Hiraide, H., and Seki, S.: IFNgamma production from liver mononuclear cell of mice in burn injury as well as in post-burn bacterial infection models and the therapeutic effect of IL-18. J. Immunol., 169, 44374442, 2002.

[14] Ono, S., Ueno, C., Seki, S., Matsumoto, A., and Hiraide, H.: Interleukin-12 and -18 induce severe liver injury in mice recovered from peritonitis after sublethal endotoxin challenge. Surgery, 134, 92-100, 2003.

[15] Fergie, J.E., Shema, S.J., Lott, L., Crawfoed, R., and Patrick, C.C.: Pseudomonas aeruginosa bacteremia in immunocompromised children: analysis of factors associated with a poor outcome. Clin. Infect. Dis., 18, 390-394, 1994.

[16] Kinosita, M., Uchida, T., Nakashima, H., Ono, S., Seki, S., and Hiraide, H.: Opposite effects of enhanced tumor necrosis factor- $\alpha$ production from Kupffer cells by gadolinium chloride on liver injury/mortality in endotoxemia of normal and partially hepatectomized mice. Shock, 23, 65-72, 2005.

[17] Seki, S., Osada, S., Ono, S., Aosasa, S., Habu, Y., Nishikage, T., Mochizuki, H., and Hiraide, H.: Role of liver NK cells and peritoneal macrophages in gamma interferon and interleukin-10 production in experimental bacterial peritonitis in mice. Infect. Immun., 66, 5286-5294, 1998.

[18] Rosen, H. and Klebanoff, S.J.: Chemiliminescence and superoxide production by myeloperoxidase-deficient leukocytes. J. Clin. Invest., 58, 50-60, 1976.

[19] Nakano, M., Sugioka, K., Ushijima, Y., and Goto, T.: Chemiluminescence probe with cypridina luciferin analog, 2methyl-6-phenyl-3,7-dihydroimidazo[1,2,-a]pyrazin-3-one, for estimating the ability of human granulocytes to generate $\mathrm{O}_{2}^{-}$. Anal. Biochem., 159, 363-369, 1986.

[20] Yamamoto, Y., Kambayashi, Y., Ito, T., Watanabe, K., and Nakano, M.: 1,2-Diacylglycerol hydroperoxides induce the generation and release of superoxide anion from human polymorphonuclear leukocytes. FEBS. Lett., 412, 461-464, 1997.

[21] Seki, S., Habu, Y., Kawamura, T., Takeda, K., Dobashi, H., Ohkawa, T., and Hiraide, H.: The liver as a crucial organ in the first line of host deference: The roles of Kupffer cells natural killer (NK) cells and NK1.1 Ag+ T cells in T helper 1 immune responses. Immunol. Rev., 174, 35-46, 2000.

[22] Grogory, S.H., Barczynski, L.K., and Wing, E.J.: Effector function of hepatocytes and Kupffer cells in the resolution of systemic bacterial infection. J. Leukoc. Biol., 51, 421-424, 
1992.

[23] Wilkinson, R.A. and Fishman, J.A.: Effect of thermal injury with Pseudomonas aeruginosa infection on pulmonary and systemic bacterial clearance. J. Trauma., 47, 912-917, 1999.

[24] Nelson, S., Belknap, S.M., Carlson, R.W., Dale, D., Deboisblanc, B, Farkas, S., Fotheringhan, N., Ho, H., Marrie, T., Movahhed, H., Root, R., and Wilson, J.: A randomized controlled trial of filgrastim as an adjunct to antibiotics for treatment of hospitalized patients with community-acquired pneumonia, CAP Study Group. J. Infect. Dis., 178, 10751080, 1998.

[25] Trinchieri, G.: Interleukin-12: a proinflammatory cytokine with immunoregulatory functions that bridge innate resistance and antigen-specific adaptive immunity. Ann, Rev. Immunil., 13, 251-276, 1995.

[26] Chan, S.H., Kobayashi, D., Perussia, B., and Trinchieri, G.: Mechanisms of IFN-gamma induction by natural killer cell stimulatory factor (NKSF/IL-12). Role of transcription and mRNA stability in the synergistic interaction between NKSF and IL-12. J. Immunol., 148, 92-98, 1992.

[27] Okamura, H., Tsutsi, H., Komatsu, T., Yutsudo, M., Hakura, A., Tanimoto, T., Torigoe, K., Okura, T., Nukada, Y., and Hattori, K.: Cloning of a new cytokine that induces IFNgamma production by T cells. Nature, 378, 88-91, 1995.

[28] Nakanishi, K., Yoshimoto, T., Tsutsui, H., and Okamura, H.:
Interleukin-18 regulates both Thi and Th2 responses. Annu. Rev. Immunol., 19, 423-474, 2001.

[29] Kinosita, M., Seki, S., Ono, S., Shinomiya, N., and Hiraide, H.: Paredoxical effect of IL-18 therapy on the severe and mild Escherichia coli infections in burn-injured mice. Ann. Surg., 240, 313-320, 2004.

[30] Goebel, A., Kavanagh, E., Lyons, A., Saporoschetz I.B., Soberg, C., Lederer, J.A., Mannick, J.A., and Rodric M.L.: Injury induces deficient interleukin-12 production, but interleukin-12 therapy sfter injury restores resistance to infection. Ann. Surg., 231, 253-261, 2000.

[31] O'Sullivan, S.T., Lederer, J.A., Horgan, A.F., Chin, D.H., Mannick, J.A., and Rodrick, M.L.: Major injury leads to predominance of the $\mathrm{T}$ helper-2 lymphocyte phenotype and diminished interleukin-12 production associated with decreased resistance to infection. Ann. Surg., 225, 482-490, 1995.

[32] O'Suilleabhain, C., O'Sullivan, S.T., Kelly, J.L., Lederer, J., Mannick, J.A., and Rodrick, M.L.: Interleukin-12 treatment restores normal resistance to bacterial challenge after burn injury. Surgery, 120, 290-296, 1996.

[33] O'Sullivan, S.T. and O'Connor, T.P.: Immunosuppression following thermal injury: the pathogenesis of immunodysfunction. Br. J. Plast. Surg., 50, 615-623, 1997. 